TAS Journal, vol. 5, n. 1, p. 13-28

ISSN 2595-1521

MARCH 2021

lubencg@sc.usp.br

\title{
Simplified approach for simulating hermetic compressor startup regime
}

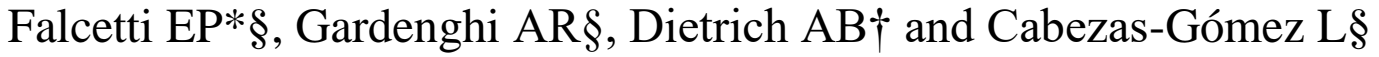 \\ *Tecumseh do Brasil LTDA, São Carlos, SP, Brasil. §Departamento de Engenharia Mecânica, \\ EESC-USP, São Carlos, SP, Brasil. †Centro de Engenharia, Modelagem e Ciências Sociais \\ Aplicadas, Universidade Federal do ABC, SP, Brasil.
}

\begin{abstract}
It is presented a hermetic compressor startup simulation procedure considering a simplified approach to obtain the transient data of different compressor parameters. The main numerical technique is a four order Runge-Kutta procedure to numerically integrate the systems of ordinary differential equations, which describe the variables' variation with time in each part of the compressor. The simulations were performed in the Windali software. The results show how the oil viscosity influences the electrical motor torque, the compressor load and crankshaft angular velocity with time for two electric motor input voltage values. The increase of oil viscosity by a factor of 2 , retards the compressor startup for more than one second. The presented simple model could be valuable for studying the geometrical and operational influence on compressor startup.
\end{abstract}

Keywords. Hermetic compressor, Numerical simulation, Startup regime.

Introduction. The present work concerns the development of a hermetic compressor startup simulation methodology to describe the temporal variation of some parameters that characterize the compressor transients in its initial working regime. The present simulation approach was solved in the Windali software, developed at the Technical University of Denmark (DTU) (1). The main modeled mechanisms are the compressor mechanism kinematics, the electrical motor behavior and the compression cylinder theoretical process. Even if the last two models should be improved they allowed to perform initial simulations and to understand better some phenomena associated with the compressor startup. Similar models, including the simulations considered in this paper can be consulted in (2) and (3).

The presented model considers the startup process with specified evaporator and condenser pressures. A second model will be developed considering the dynamical change of the evaporator and condenser pressures and temperatures for future simulations. This type of model will be incorporated into the refrigeration system simulation methodology presented in (4) to improve the system startup regime modeling. In the following sections are described the main details of the present paper including the model formulation, results presentation and paper conclusions.

Theoretical model. Follows the mathematical model solved in the Windalli software. 
Compression mechanism kinematic relations. In this section are given all the geometrical, kinematical, force and torque formulations needed to simulate the compressor.

This section contains the equations describing the relations between the oscillating motion of the piston and the rotating motion of the crankshaft. The derivation of these equations can be found in (5) and (6), among other works. The equations where derived with the starting rotation angle at the Top dead center (TDC) and considering a piston offset. The equations relating crankshaft angle to piston position can be derived from geometrical observations. Next are presented the main relations.

The instantaneous position of the piston $\mathrm{Z}(\mathrm{t})$, in [m], and sweep volume $\mathrm{V}(\mathrm{t})$, in [m3], as a function of crankshaft angle are expressed as:

$$
\begin{aligned}
& Z(t)=R_{1} \cos \theta(t)+\sqrt{R_{2}^{2}-\left(R_{1} \sin \theta(t)-h\right)^{2}} \\
& V(t)=V_{c}+A_{p}\left[\sqrt{\left(R_{2}+R_{1}\right)^{2}-h^{2}}-R_{1} \cos \theta(t)-\sqrt{R_{2}^{2}-\left(R_{1} \sin \theta(t)-h\right)^{2}}\right]
\end{aligned}
$$

In the above relations $\mathrm{V}_{\mathrm{c}}$ is the clearance volume $\left[\mathrm{m}^{3}\right], \mathrm{R}_{1}$ and $\mathrm{R}_{2}$ represent the crankshaft radius and connecting rod length $[\mathrm{m}]$, respectively, Ap means the cross-section area of the piston $\left[\mathrm{m}^{2}\right], \theta(\mathrm{t})$ stands for the crankshaft rotation angle with origin at TDC [rad] and $\mathrm{h}$ is the piston offset $[\mathrm{m}]$. Note that the sweep volume is equal to $\mathrm{V}(\mathrm{t})=\mathrm{V}_{\mathrm{c}}+\mathrm{A}_{\mathrm{p}}\left[\mathrm{Z}_{\max }-\mathrm{Z}(\mathrm{t})\right]$, where $\mathrm{Z}_{\max }$ represents the maximum piston position $[\mathrm{m}]$ :

$Z_{\text {max }}=\sqrt{\left(R_{1}+R_{2}\right)^{2}-h^{2}}$

The piston velocity $\mathrm{V}_{\mathrm{p}}(\mathrm{t})[\mathrm{m} / \mathrm{s}]$ is calculated by:

$V_{p}(t)=\frac{d Z(t)}{d t}=-\frac{d V(t)}{d t} / A_{p}=\varpi(t) \cdot R_{1}\left[\sin \theta(t)+\frac{\cos \theta(t)\left(R_{1} \sin \theta(t)-h\right)}{\sqrt{R_{2}^{2}-\left(R_{1} \sin \theta(t)-h\right)^{2}}}\right]$

where $\varpi(t)$ represents the crankshaft angular velocity $[\mathrm{rad} / \mathrm{s}]$. The angular velocities of the connecting rod in the piston pin, $\varpi_{\mathrm{p}}(\mathrm{t})$, in $[\mathrm{rad} / \mathrm{s}]$, and of the connecting rod in the crankshaft, $\varpi_{\mathrm{k}}(\mathrm{t})$, in $[\mathrm{rad} / \mathrm{s}]$, are expressed as:

$$
\begin{aligned}
& \varpi_{p}(t)=\frac{R_{1} \varpi(t) \cos \theta(t)}{\sqrt{R_{2}^{2}-\left(R_{1} \sin \theta(t)-h\right)^{2}}} \\
& \varpi_{k}=-\varpi_{p}-\varpi
\end{aligned}
$$


The crankshaft rotation angle and angular velocity are related by:

$\varpi(t)=\frac{d \theta(t)}{d t}$

where $\mathrm{t}$ is the time instant in [s]. When the crankshaft rotates with constant angular velocity the above relation can be written as:

$\varpi(t)=\theta(t) / t$

Considering the more general case, namely, a variable crankshaft angular velocity, the piston acceleration $\mathrm{P}_{\mathrm{ac}}\left[\mathrm{m} / \mathrm{s}^{2}\right]$ is computed as:

$P_{a c}=\frac{d^{2} Z(t)}{d t^{2}}=\varpi(t)^{2} \frac{d^{2} Z}{d \theta^{2}}(t)+\frac{d \varpi(t)}{d t} \frac{d Z}{d \theta}(t)$

For a constant crankshaft angular velocity the last term of the right hand size is null. This term includes the crankshaft angular acceleration in $\left[\mathrm{rad} / \mathrm{s}^{2}\right]$. In the above relation the following expressions are used:

$$
\begin{aligned}
& \frac{d Z}{d \theta}(t)=R_{1}\left[\sin \theta(t)+\frac{\cos \theta(t)\left(R_{1} \sin \theta(t)-h\right)}{\sqrt{R_{2}^{2}-\left(R_{1} \sin \theta(t)-h\right)^{2}}}\right] \\
& \frac{d^{2} Z}{d \theta^{2}}(t)=R_{1}\left\{\cos \theta(t)+\frac{R_{1}\left(2 \cos ^{2}(\theta(t))-1\right)+h \sin \theta(t)}{\sqrt{R_{2}^{2}-\left(R_{1} \sin \theta(t)-h\right)^{2}}}+\frac{R_{1} \cos ^{2}(\theta(t))\left(R_{1} \sin \theta(t)-h\right)^{2}}{\left(R_{2}^{2}-\left(R_{1} \sin \theta(t)-h\right)^{2}\right)^{3 / 2}}\right\}
\end{aligned}
$$

The temporal angular acceleration is computed from a mechanical total energy balance. This is very important to simulate the startup process of a compressor. In these cases, the piston acceleration should be computed only after the computation of the crankshaft angular acceleration.

Total mechanical energy considerations. The change in the mechanical total energy can be expressed by the following equation (3):

$$
\sum\left(\tau_{i}(t) \varpi_{i}(t)\right)+\sum\left(\vec{F}_{i}(t) \bullet \frac{d \vec{Z}(t)}{d t}\right)=\frac{d}{d t}\left(\frac{1}{2} m_{o s c l}\left(\frac{d Z(t)}{d t}\right)^{2}+\frac{1}{2} J_{r o t} \varpi(t)^{2}\right)
$$


The equation expresses that the work done by all external torques, $\tau_{\mathrm{i}},[\mathrm{N} \mathrm{m}]$ acting on the crankshaft and in the bearing, and all external forces, $\mathrm{F}_{\mathrm{i}},[\mathrm{N}]$ acting on piston are equal to the change in the total mechanical energy of the system. In this equation, the work done by external forces acting on the system through the suspension system and changing the position and orientation of the mechanical system are neglected. Furthermore, changes in the potential energy of the components are neglected. Since not all torques acting on the system are related to bearings having the same angular velocity as the crankshaft, local angular velocities in the bearings are considered.

The above expression is used to compute how the angular velocity of the crankshaft or the motor speed changes with time, in the case of considering a transient startup simulation. Making the necessary manipulations, the Eq. (12) can be written as:

$$
\frac{d \varpi(t)}{d t}=\frac{\sum\left(\tau_{i}(t) \frac{\varpi_{i}(t)}{\varpi(t)}\right)+\sum\left(F_{i}(t) \frac{d Z}{d \theta}(t)\right)-m_{\text {oscl }} \varpi(t)^{2} \frac{d Z}{d \theta}(t) \frac{d^{2} Z}{d \theta^{2}}(t)}{m_{\text {oscl }}\left(\frac{d Z}{d \theta}(t)\right)^{2}+J_{\text {rot }}}
$$

The calculation of the mass of oscillating components, $\mathrm{m}_{\mathrm{oscl}},[\mathrm{kg}]$ is complicated because the movement of the connecting rod is a combination of both a translation and rotating motion. The end of the connecting rod connected to the crankshaft performs a rotational movement whereas the end connected to the piston performs an oscillating movement. One manner to deal with this combined motion is to split the mass of the connecting rod into two parts: a rotational part and an oscillating part. For small compressors it is a common practice to consider the $85 \%$ of the connecting rod as a rotating mass and $15 \%$ as an oscillating mass. Thus, the following relations hold:

$$
m_{\text {oscl }}=m_{\text {pist }}+m_{\text {pin }}+0.15 m_{\text {rod }}
$$

where $\mathrm{m}_{\text {pist }}, \mathrm{m}_{\text {pin }}$ and $\mathrm{m}_{\text {rod }}[\mathrm{kg}]$ are the masses of the piston, piston pin and connecting rod respectively. The factor 0.15 for the mass of the connecting rod is based on an estimation of the position of the center of gravity for the connecting rod.

For the rotating masses the total moment of inertia $\mathrm{J}_{\text {rot }}\left[\mathrm{kg} \mathrm{m}^{2}\right]$ can be calculated as:

$$
J_{\text {rot }}=J_{\text {rotor }}+J_{\text {crank }}+J_{\text {rod }}
$$

where $\mathrm{J}_{\text {rotor }}, \mathrm{J}_{\text {crank }}$ and $\mathrm{J}_{\text {rod }}$ stand for the rotor, crankshaft and connecting rod moment of inertia, $\left[\mathrm{kg} \mathrm{m}^{2}\right]$. The first two quantities are computed by the following general expression:

$$
J=m r^{2}
$$


where $\mathrm{m}$ is the component mass, $[\mathrm{kg}]$ and $\mathrm{r}$ is the component mean radius $[\mathrm{m}]$. The connecting rod moment of inertia is calculated as:

$$
J_{\text {rod }}=0.85 \cdot m_{\text {rod }} r^{2}
$$

These three quantities are input data for the Windali program.

Compressor loads and power loss. The main external torques acting on the system are: the torque developed by motor with angular velocity, $\varpi$; the friction torques in all compressor bearings (crankshaft bearing, crank-pin bearing and connecting rod-piston pin bearing); the torque needed to operate the oil pump and the friction torque in gas gap between rotor and stator. According to Rasmussen (6) the last two terms can be neglected because they cause loads of about $10 \mathrm{~mW}$ approximately.

The external forces acting on the system can be divided into two groups: forces acting on piston and forces acting on system through the suspension system. The work done by the forces acting on the system through the suspension system is neglected. The main forces acting on the piston are: the gas force, $\mathrm{F}_{\text {gas }}[\mathrm{N}]$; the friction force due to viscous friction in oil film, $\mathrm{F}_{\mathrm{oil}}$; [N] and the force from connecting rod acting on piston bearing, $\mathrm{F}_{\text {rod }}[\mathrm{N}]$. Other two forces act over the piston but will not be used in the present approach, namely the friction force due to guide force on piston and the guide force on piston skirt.

The following loads are considered to compute the mechanical compressor loads: (i) Load on piston from gas in the cylinder, (ii) load from acceleration/deceleration of oscillating mass, (iii) Frictional loads in bearings, and (iv) the viscous frictional loads in the piston-cylinder assembly. Thus, the crankshaft torque is the sum of: $\mathrm{Tq}_{\text {crank }}=\mathrm{Tq}_{\text {gas }}+\mathrm{Tq}_{\mathrm{oscl}}+\mathrm{Tq}_{\text {bear }}+\mathrm{T} \mathrm{q}_{\text {pis-cyl }}[\mathrm{N}$ $\mathrm{m}]$, respectively.

The gas force exerted by the gas on the compressor piston is computed by:

$$
F_{\text {gas }}=A_{p}\left(p_{c y l}-p_{\text {shell }}\right)
$$

where $\mathrm{p}_{\text {cyl }}$ and $\mathrm{p}_{\text {shell }}$ are the gas pressure in the cylinder and shell, $[\mathrm{Pa}]$, respectively. The external work due to the gas action, $[\mathrm{J}]$, and the load on piston, and consequently on the crankshaft, from this gas force, [W], are expressed as:

$T q_{\text {gas }}=F_{\text {gas }} \cdot \frac{d Z}{d \theta}(t) \quad$ and $\quad L d_{\text {gas }}=T q_{g a s} \cdot|\varpi(t)|$

The change in mechanical energy (translational) and the crankshaft load due to acceleration/deceleration of oscillating masses are formulated as:

$T q_{o s c l}=m_{o s c l} \varpi(t)^{2} \frac{d Z}{d \theta}(t) \frac{d^{2} Z}{d \theta^{2}}(t) \quad$ and $\quad L d_{o s c l}=T q_{o s c l} \cdot|\varpi(t)|$ 
Note that the energy and power obtained by the external gas force action, as well as, the power obtained by the change in mechanical kinetic energy due to oscillating masses can be negative or positive.

When it is computed the compressor efficiency in one compressor cycle one of the main parameters to be computed are the power loss. These losses are equal to the sum of pistoncylinder viscous friction loss and the frictional loads, and consequently energy losses, in bearings. In the present Windali code all frictional losses in bearing are computed using the simplified Petrov relation described as:

$T q_{\text {bear }}=2 \pi \mu_{\text {oil }} \varpi(t) \frac{r^{3} L}{c}$ and $L d_{\text {bear }}=\left|T q_{\text {bear }} \cdot \varpi(t)\right|$

The piston-cylinder viscous friction losses are computing following Bukac (2002) as:

$T q_{p i s t-c y l}=\frac{\pi \mu_{o i l} D_{p} L_{p}}{\left(D_{c y l}-D_{p}\right)} \frac{V_{p}^{2}}{\varpi(t)}$ and $L d_{p i s t-c y l}=\left|T q_{p i s t-c y l} \cdot \varpi(t)\right|$

where $\mathrm{D}_{\text {cyl }}[\mathrm{m}]$ stands for the cylinder diameter.

Considering all the formulae presented in these sections, the temporal derivative of the crankshaft angular velocity from Eq. (13) is rewritten as:

$$
\frac{d \Phi(t)}{d t}=\frac{T q_{\text {motor }}-\left(T q_{\text {gas }}+T q_{\text {bear }}+T q_{\text {pist-cyl }}+T q_{\text {oscl }}\right)+T q_{\text {start }}}{m_{\text {oscl }}\left(\frac{d Z}{d \theta}(t)\right)^{2}+J_{\text {rot }}}
$$

In Eq. (22) $\mathrm{T}_{\mathrm{qstart}}$ stands for the electric motor starting torque, [N m].

Compression cylinder process. To model the cylinder pressure and temperature values it is used a simple theoretical polytropic model for the compression and expansion processes. For the discharge and suction process it is assumed that the pressure is equal to the pressures at the condenser and evaporator, respectively. The following relations where apply to model one entire compressor cycle, starting from the TDC point:

Expansion process:

$$
P_{c y l}=P_{c o n d} \cdot\left(V_{c y l \text { min }} / V_{c y l}\right)^{\frac{1}{k_{\text {exp }}}}
$$


Suction process:

$$
P_{c y l}=P_{\text {evap }}
$$

Compression process:

$$
P_{c y l}=P_{\text {evap }} \cdot\left(V_{c y l, \max } / V_{c y l}\right) \frac{1}{k_{c o m p}}
$$

Discharge process:

$$
P_{c y l}=P_{c o n d}+\Delta P_{c o n d}
$$

In the above four relations $\mathrm{k}$ is the polytropic exponent. This exponent changes as a function of the thermodynamic processes that are identified by the sub-indices comp and exp; i.e. compression and expansion. $\mathrm{V}$ is the gas volume in the cylinder $\left[\mathrm{m}^{3}\right]$. In these cases the subindices $c y l$, cyl,max and cyl,min are used to denote the current volume of the cylinder, the volume at the suction condition (maximum volume) and the volume at the discharge condition (minimum volume), respectively. The other two sub-indices stand respectively for the evaporator and condenser (evap and cond). In Eq. (26) the last terms denoted by $\Delta \mathrm{P}_{\text {cond, in }}[\mathrm{Pa}]$, was included to simulate, if desired, a pressure drop or head loss in the discharge tract, to see how the pressure drop affects the start-up of the compressor.

Electrical motor model. Electric motor is modeled by the procedure published in (7). That author presents a model to simulate an induction motor using the Steinmetz circuit model of one phase of a polyphase induction machine (7). In this model the motor torque is computed by:

$T q_{\text {motor }}=V^{2} \cdot \frac{A_{1} \cdot s}{B_{2} \cdot s^{2}+B_{1} \cdot s+1}$

In relation (27) s stands for the motor slip, $\mathrm{V}$ is the applied terminal voltage [V], $\mathrm{A}_{1}$ is constant $\left[(\mathrm{N} \mathrm{m}) / \mathrm{V}^{2}\right]$ and $\mathrm{B}_{1}$ and $\mathrm{B}_{2}$ are dimensionless constants of the model. The motor slip is computed as:

$$
s=\frac{\varpi_{s}-\varpi}{\varpi_{s}}
$$

The parameter $\varpi_{\mathrm{s}}$ is the synchronous angular velocity [1/s] of the rotating field. Was taken equal to $377[1 / \mathrm{s}]$. To find the above three constants only three torque-speed pairs are necessary (7). One pair is always known. It is zero torque at synchronous speed where slip is 
equal to zero. Second pair is locked-rotor torque at which the slip is equal one. The third torquespeed pair is the breakdown torque and breakdown slip at which the torque-speed curve has its local maximum.

Constant $\mathrm{B}_{2}$ corresponds to the breakdown torque and breakdown slip, $\mathrm{S}_{\mathrm{M}}$, where the torque has the maximum value and the derivative of Eq. (27) is equal to zero. In this case:

$$
B_{2}=\frac{1}{s_{M}^{2}}
$$

The breakdown slip is an input data to the model. Substituting the constant $\mathrm{B}_{2}$ in the Eq. (27) and making the necessary operations (7) the following relations are found for the other two constants:

$$
A_{1}=\frac{T_{L} T_{M}\left(2 s_{M}-s_{M}^{2}-1\right)}{V_{n o m}^{2} \cdot s_{M}^{2}\left(T_{L}-T_{M}\right)}
$$

and

$$
B_{1}=\frac{2 T_{M} s_{M}-T_{L}\left(s_{M}^{2}+1\right)}{s_{M}^{2}\left(T_{L}-T_{M}\right)}
$$

in relations (30) and (31) TM represents the maximum (breakdown) torque $[\mathrm{N} \mathrm{m}]$ and $\mathrm{T}_{\mathrm{L}}$ is the locked-rotor torque [N m].

In the Windali program this motor model was used considering the motor constants provided in (7). The main aim was to test this motor model and to make a parametric analysis of the influence of some compressor parameters over the compressor startup. These input data where: Nominal voltage $115 \mathrm{~V}$, test frequency $60 \mathrm{~Hz}$, breakdown torque $1.25 \mathrm{~N} \mathrm{~m}$, breakdown slip 0.2 , and locked-rotor torque $0.5 \mathrm{~N} \mathrm{~m}$.

Simulation results. In this section are presented some qualitative results obtained with the present approach using the induction motor model of (7) in the Windali software. For simulations are considered the following evaporator and condenser pressures: $\mathrm{P}_{\text {evap }}=200644.5$ $[\mathrm{Pa}]$ and $\mathrm{P}_{\text {cond }}=1590676.0[\mathrm{~Pa}]$.

The results are presented in Figs. $1-6$ as a function of time. The time interval considered is equal to one second. The main aim is to show quantitatively how the oil viscosity and input voltage influence some of the compressor parameters. As expected the augmentation of oil viscosity decreases the crankshaft angular velocity augmentation. This behavior is accentuated for smaller input motor voltage. In this last case, even one second is not enough to attend the nominal angular velocity (Fig. 2b). Higher values of oil viscosity will lead to a fail in the compressor startup. 
TAS Journal, vol. 5, n. 1, p. 13-28

ISSN 2595-1521

MARCH 2021

lubencg@sc.usp.br

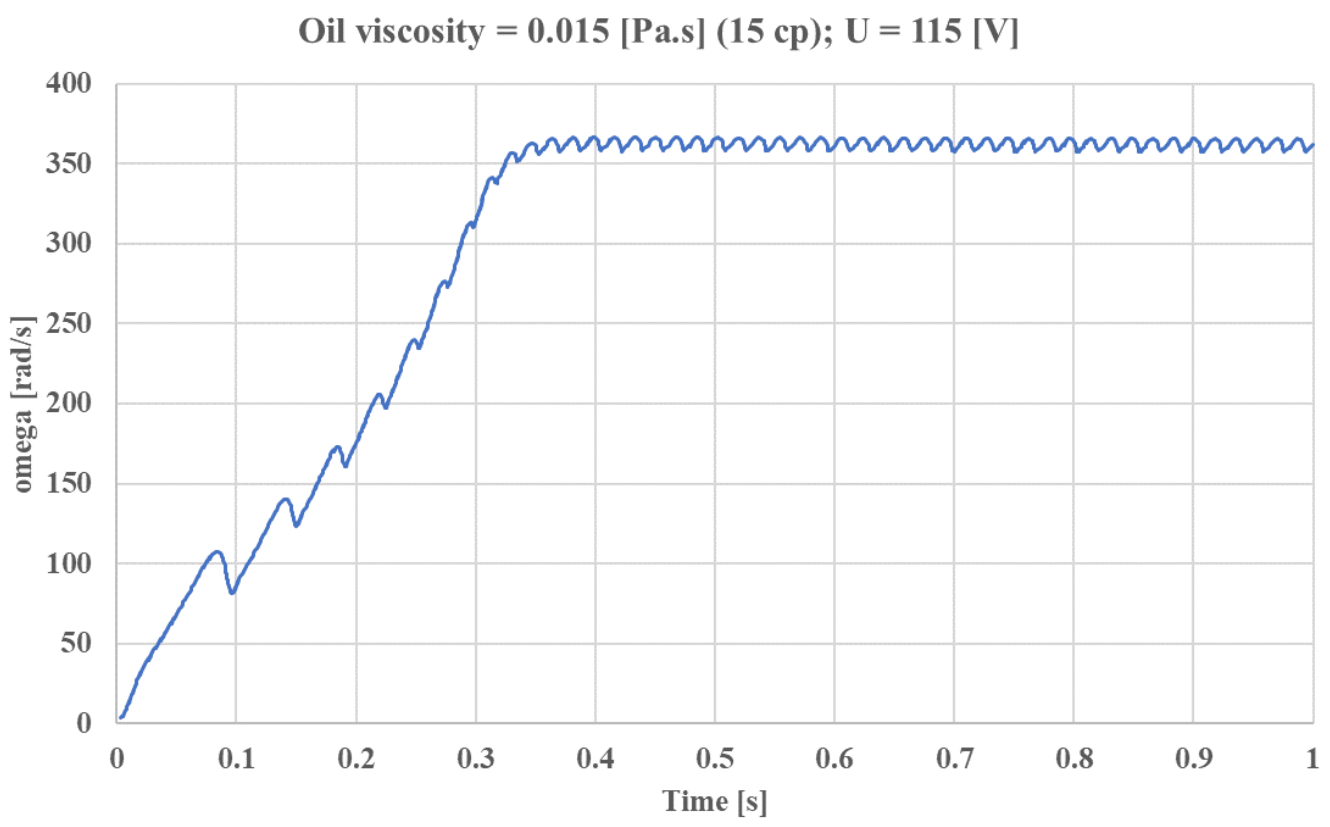

(a)

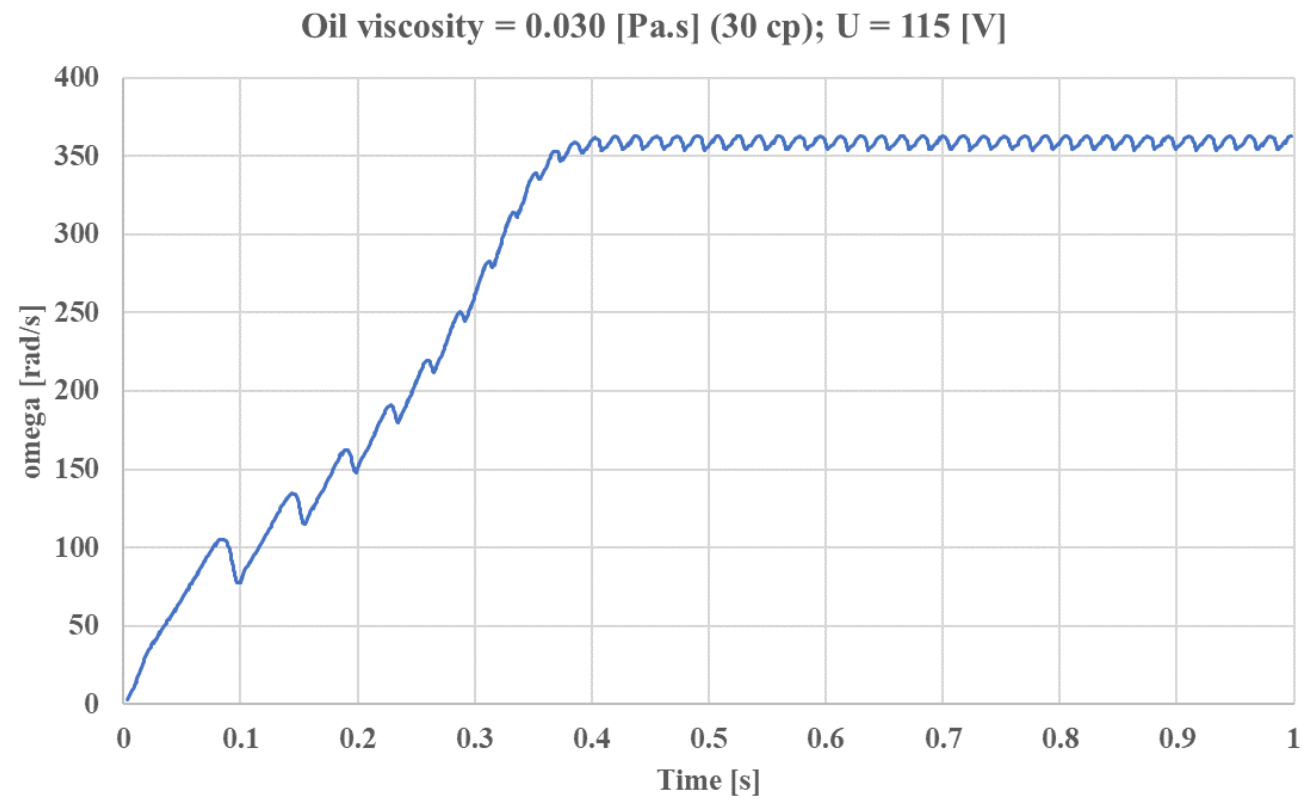

(b)

Figure 1. Crankshaft angular velocity changing with time at $\mathrm{U}=115 \mathrm{~V}$. a-) $\mu_{\mathrm{oil}}=0.015 \mathrm{~Pa}-\mathrm{s}, \mathrm{b}-$-) $\mu_{\text {oil }}=0.03 \mathrm{~Pa}-\mathrm{s}$. 
TAS Journal, vol. 5, n. 1, p. 13-28

ISSN 2595-1521

MARCH 2021

lubencg@sc.usp.br

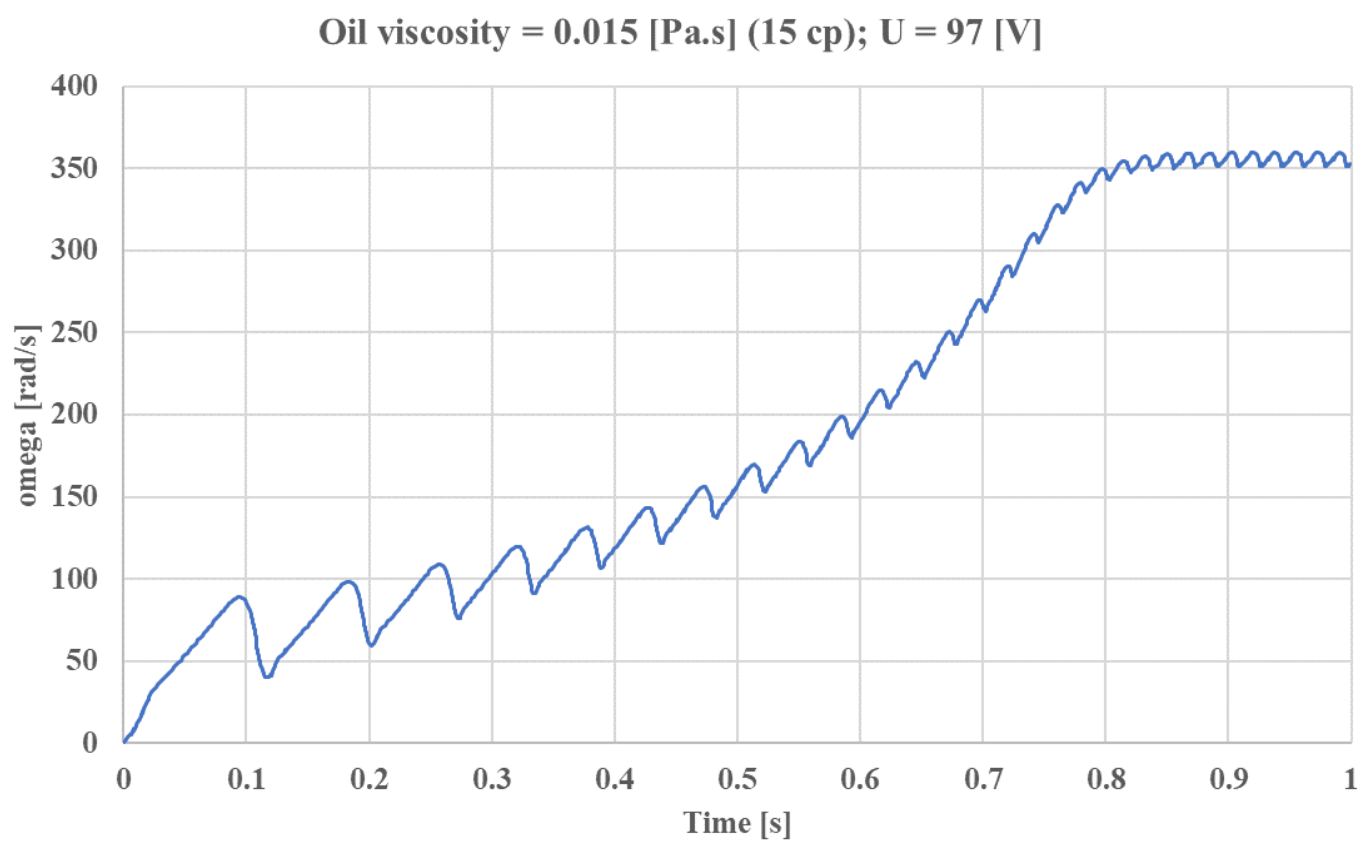

(a)

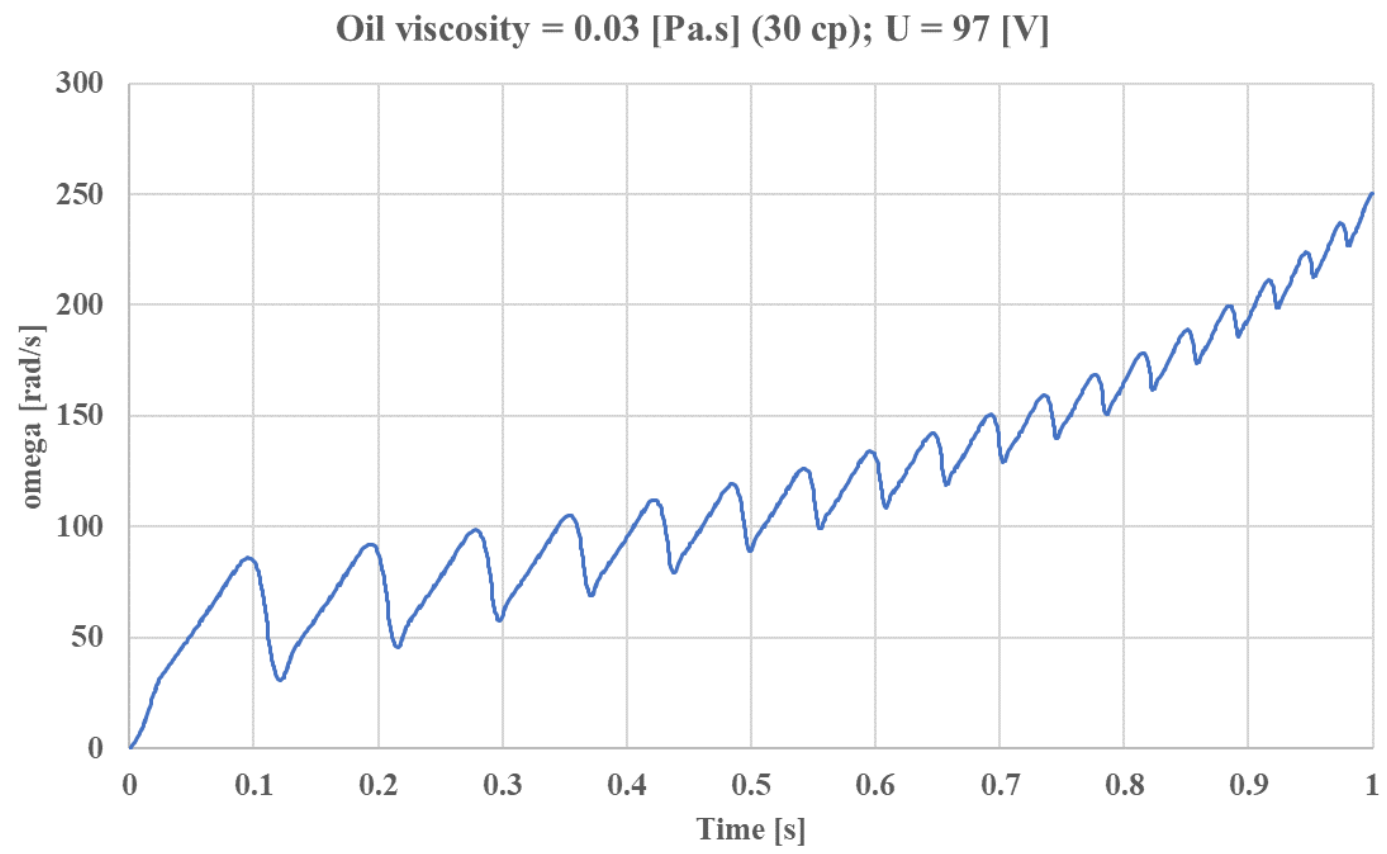

(b)

Figure 2. Crankshaft angular velocity changing with time at $U=97 \mathrm{~V}$. a-) $\left.\mu_{\mathrm{oil}}=0.015 \mathrm{~Pa}-\mathrm{s}, \mathrm{b}-\right)$ $\mu_{\text {oil }}=0.03$ Pa-s. 
TAS Journal, vol. 5, n. 1, p. 13-28

ISSN 2595-1521

MARCH 2021

lubencg@sc.usp.br

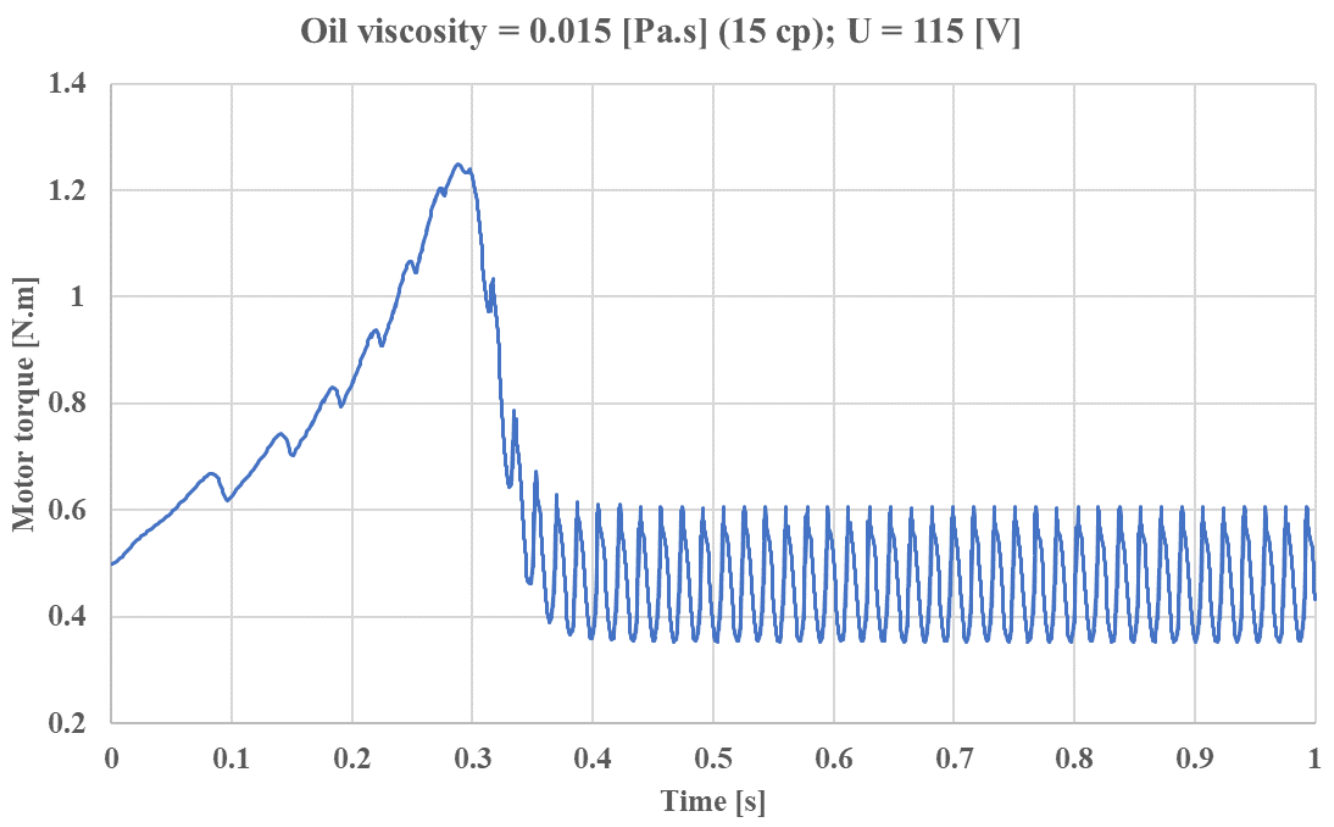

(a)

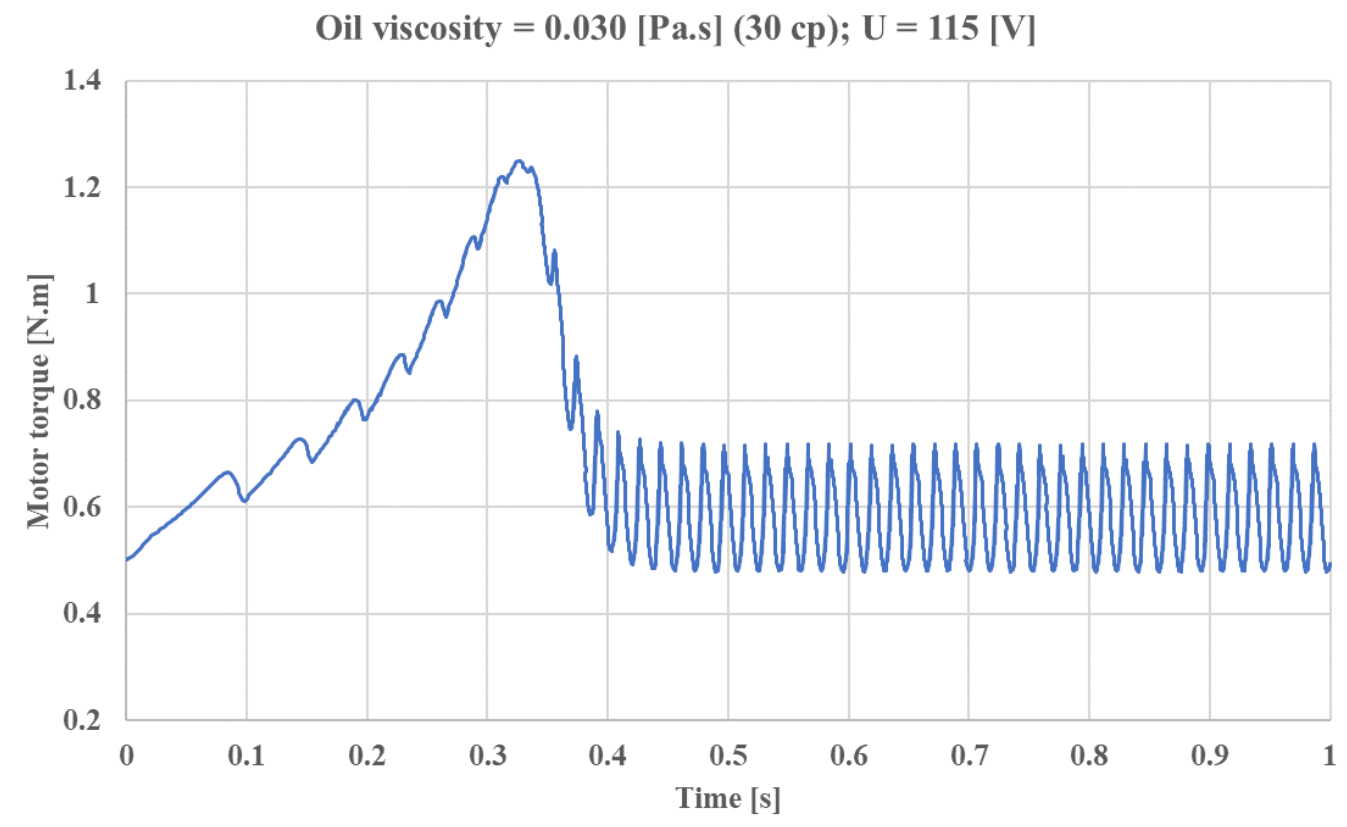

(b)

Figure 3. Motor torque variation with time $U=115 \mathrm{~V}$. a-) $\mu$ oil $=0.015 \mathrm{~Pa}-\mathrm{s}, \mathrm{b}-) \mu$ oil $=0.03 \mathrm{~Pa}-$ S. 
TAS Journal, vol. 5, n. 1, p. 13-28

ISSN 2595-1521

MARCH 2021

lubencg@sc.usp.br

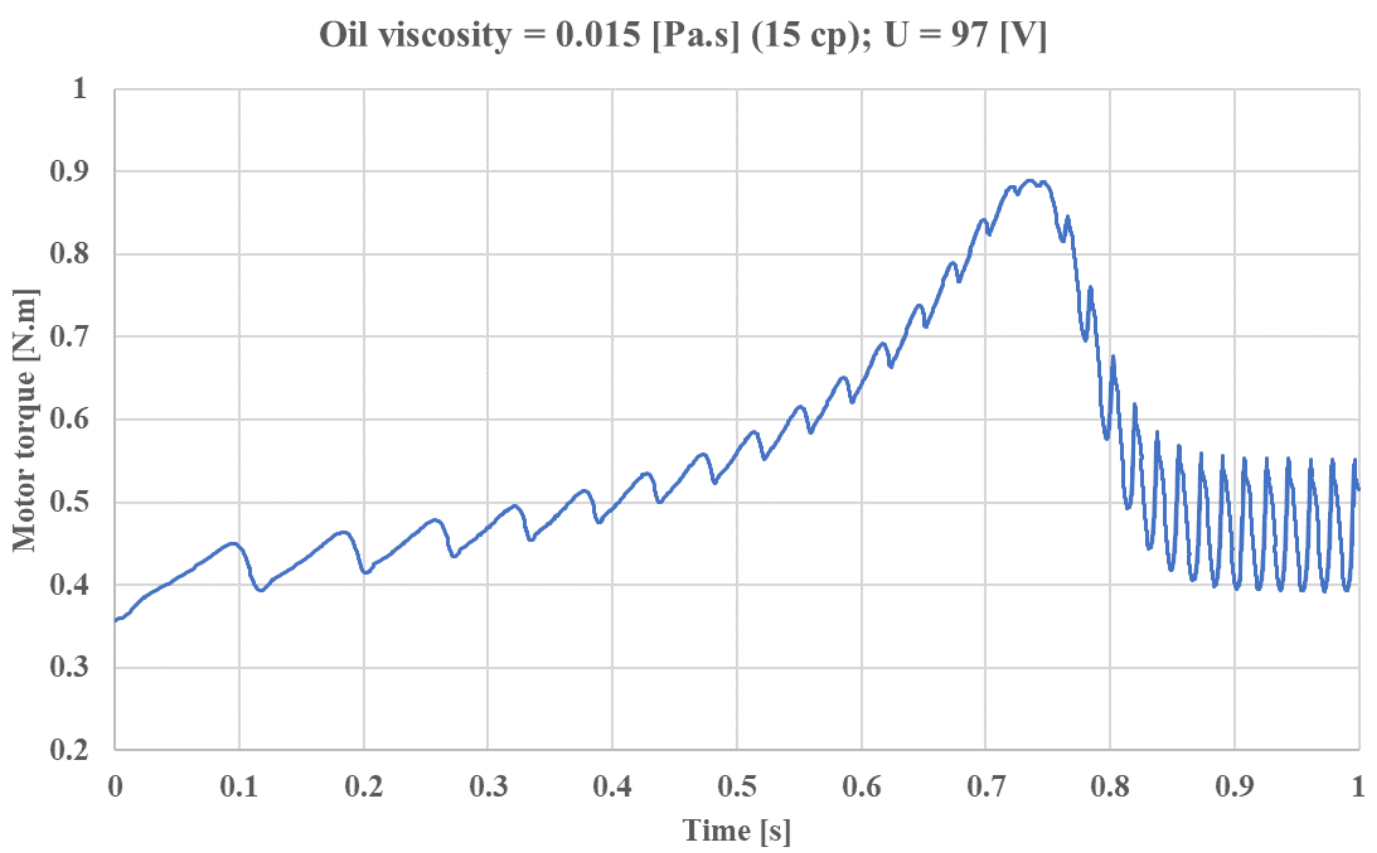

(a)

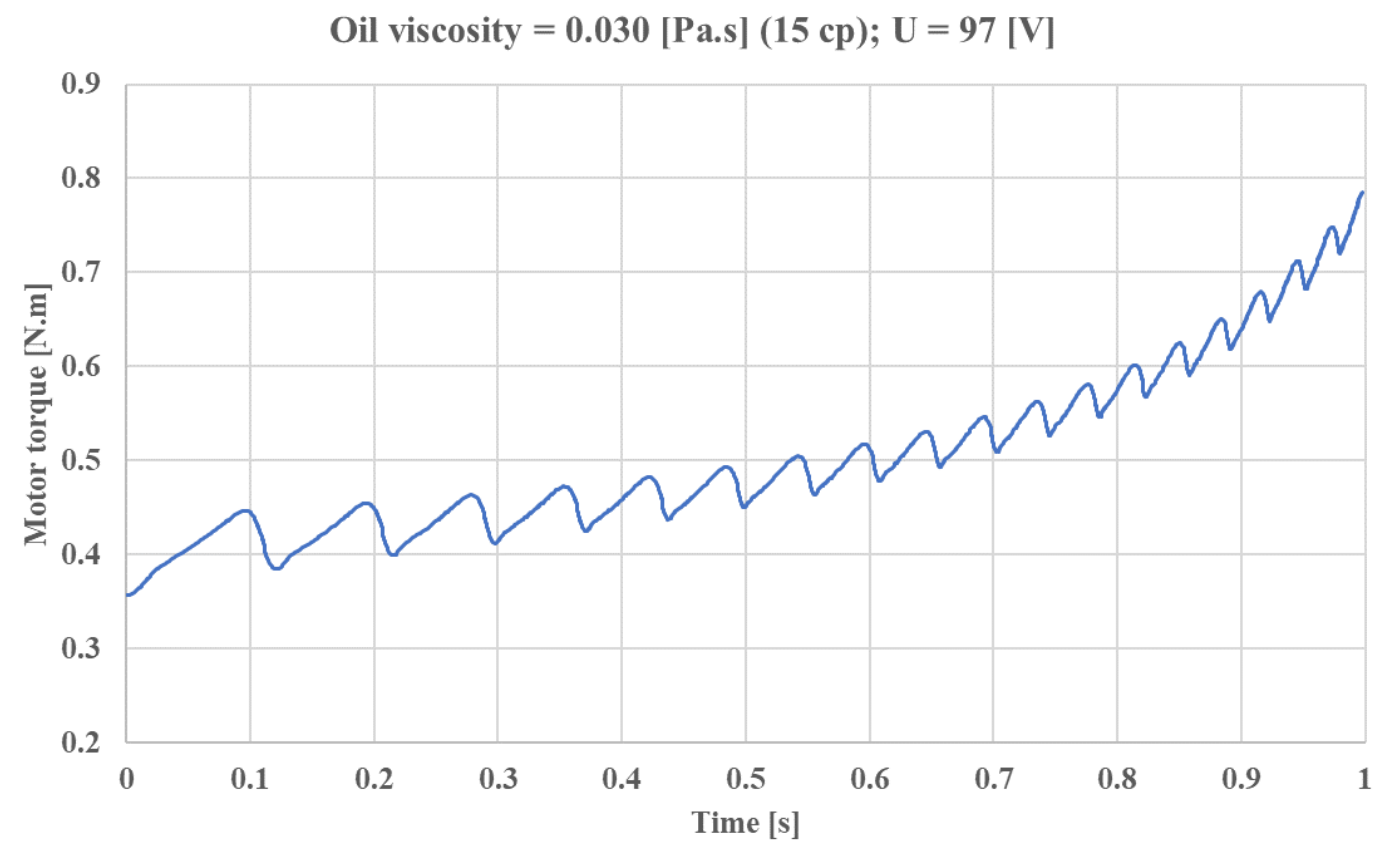

(b)

Figure 4. Motor torque variation with time $U=97 \mathrm{~V}$. a-) $\left.\mu_{\mathrm{oil}}=0.015 \mathrm{~Pa}-\mathrm{s}, \mathrm{b}-\right) \mu_{\mathrm{oil}}=0.03 \mathrm{~Pa}$-s. 
TAS Journal, vol. 5, n. 1, p. 13-28

ISSN 2595-1521

MARCH 2021

lubencg@sc.usp.br

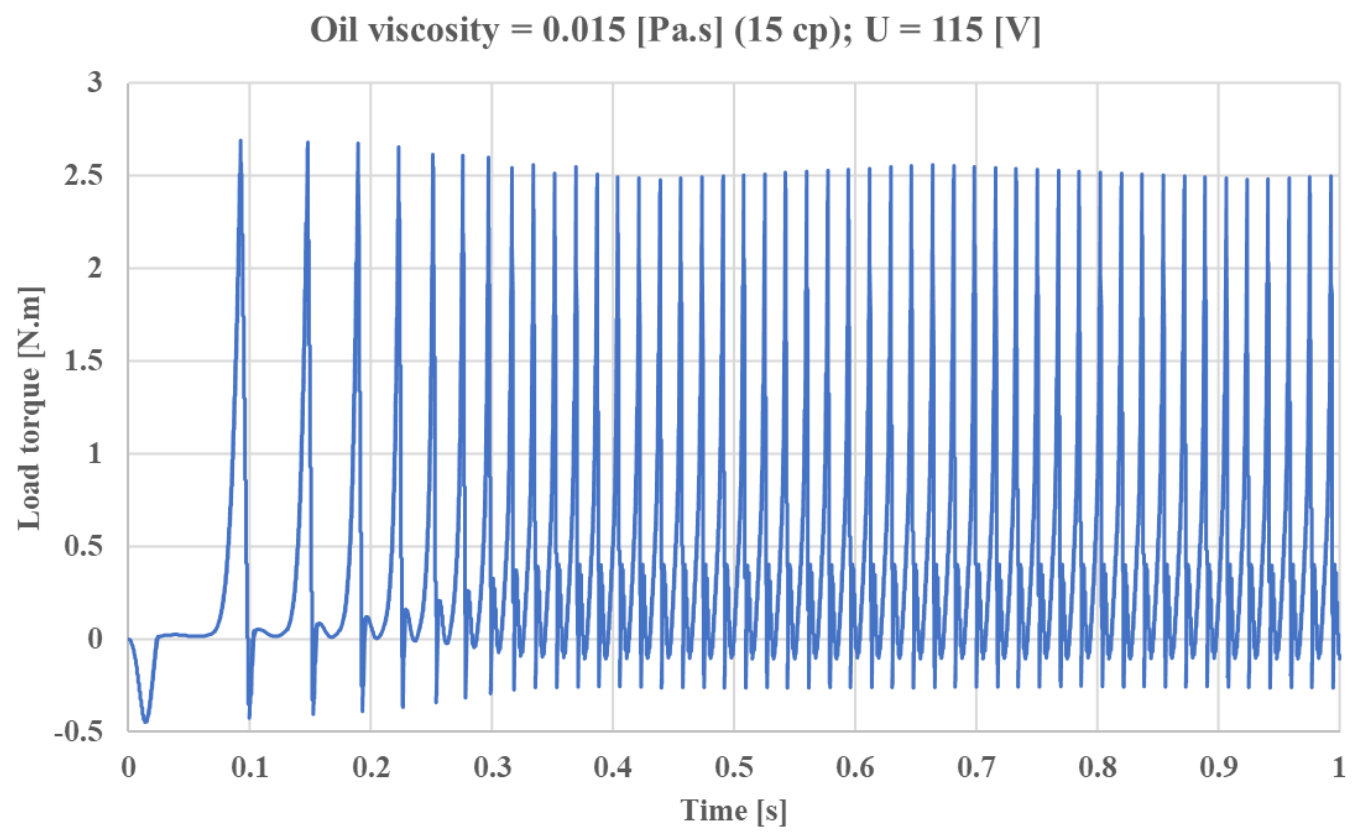

(a)

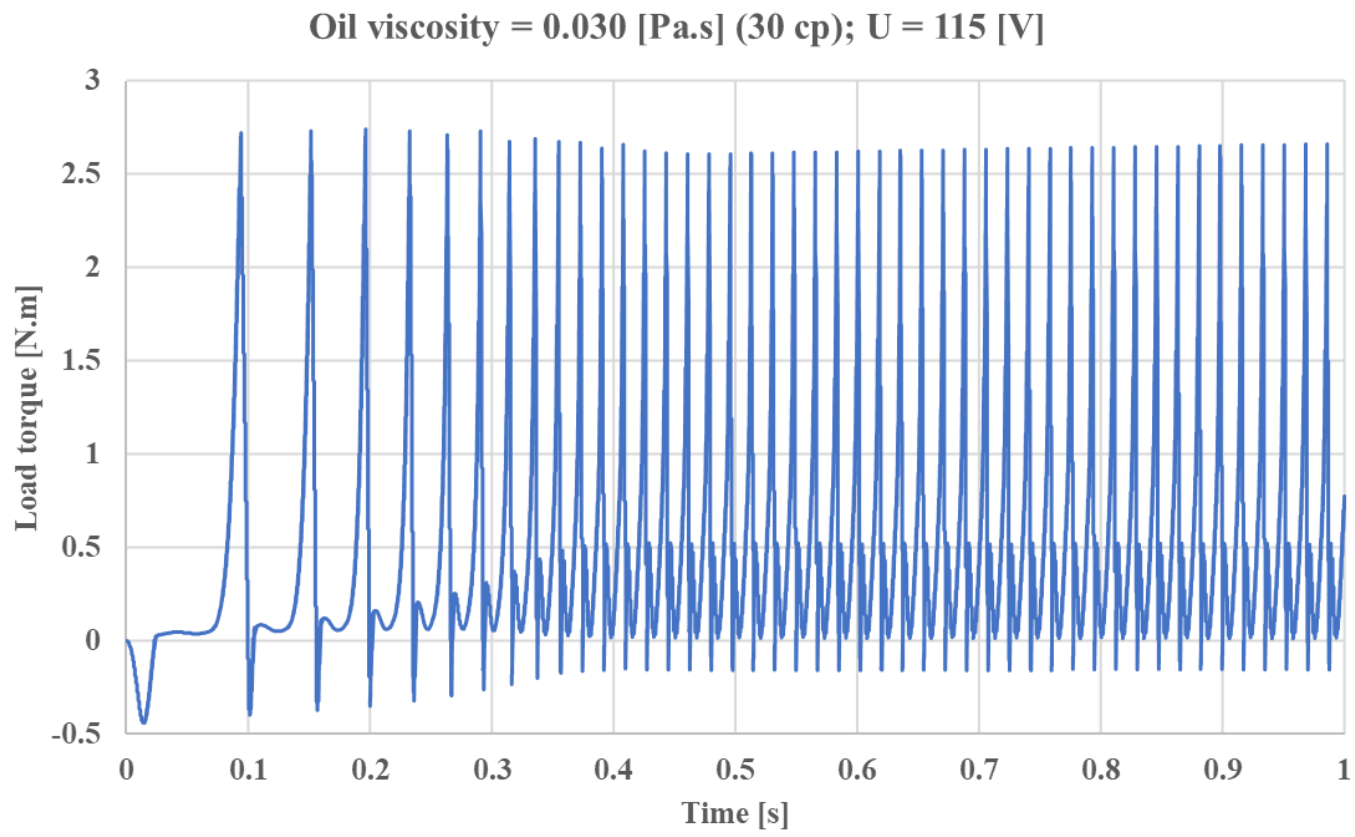

(b)

Figure 5. Crankshaft torque variation with time at $U=115 \mathrm{~V}$. a-) $\mu_{\text {oil }}=0.015$ Pa-s, b-) $\mu_{\text {oil }}=$ 0.03 Pa-s. 
TAS Journal, vol. 5, n. 1, p. 13-28

ISSN 2595-1521

MARCH 2021

lubencg@sc.usp.br

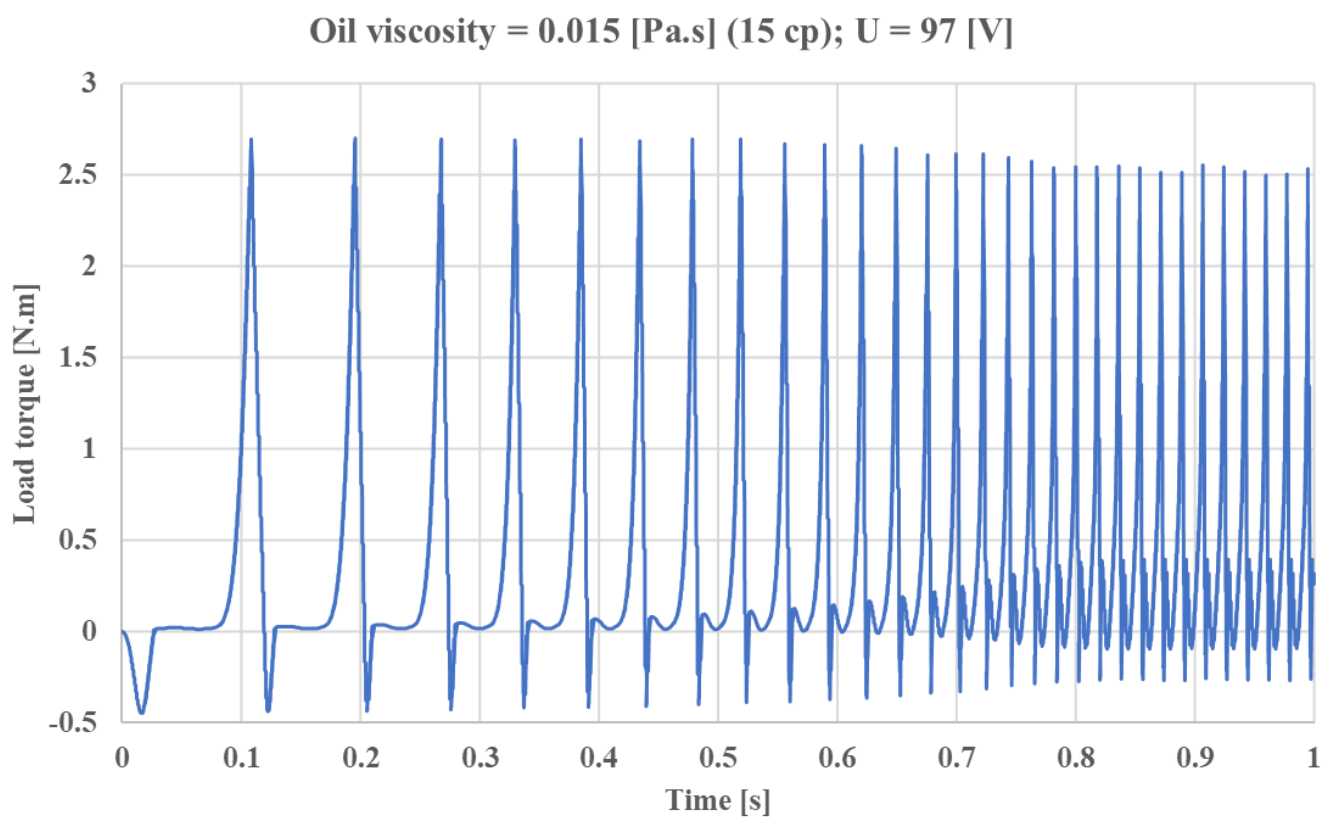

(a)

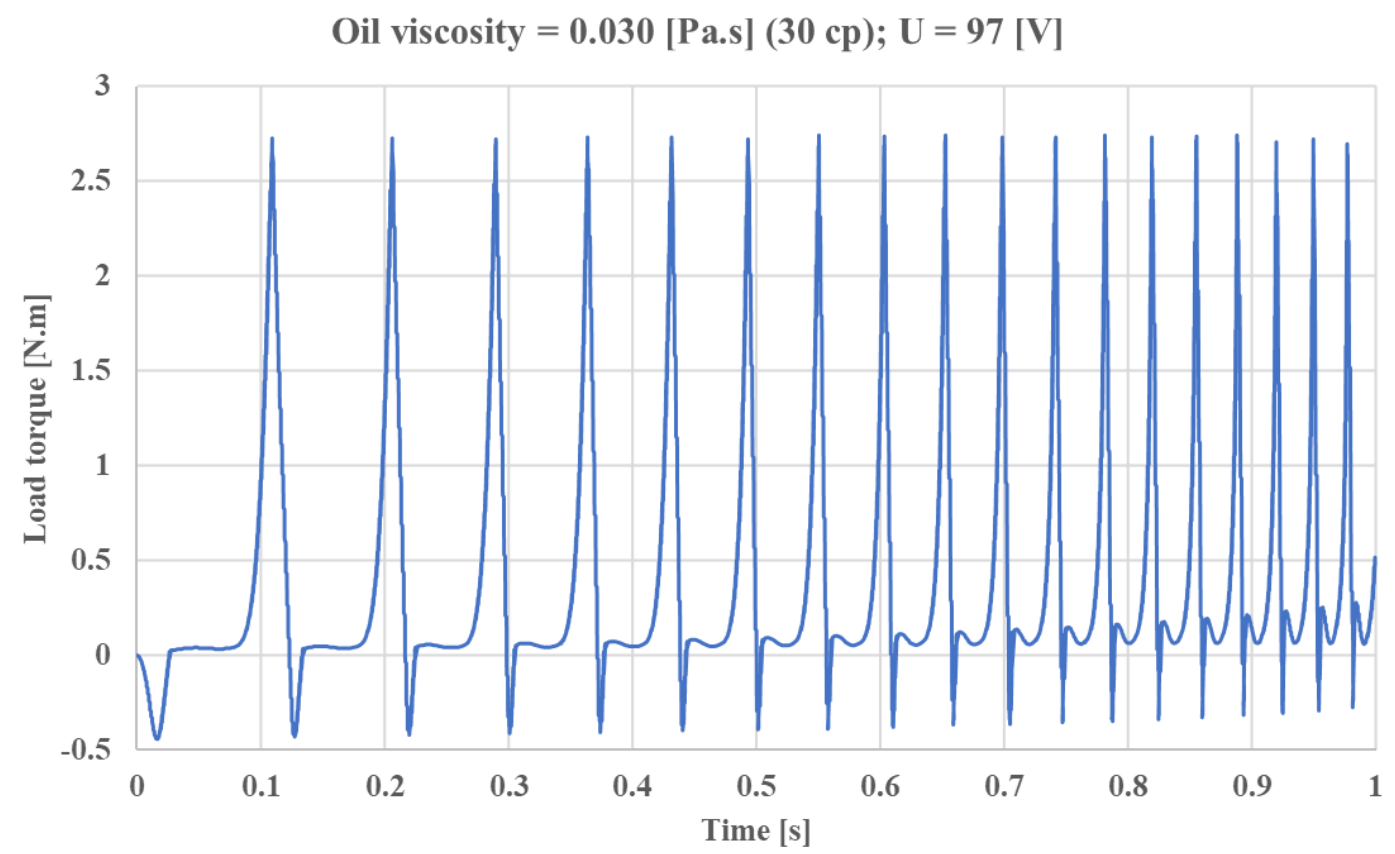

(b)

Figure 6. Crankshaft torque variation with time at $\mathrm{U}=97 \mathrm{~V}$, a-) $\mu_{\mathrm{oil}}=0.015$ Pa-s, b-) $\mu_{\mathrm{oil}}=0.03$ Pa-s. 
The resulting torque from the electrical motor also suffers with the viscosity increase. For higher viscosity the motor needs more time to reach the steady state, and the torque needed if slightly higher (c.f. Fig. 3). This increases the energy consumption of the motor and consequently of the compressor in the startup phase. The motor input voltage influences to a more extent causing the behavior shown in Fig. 4. In this case the oil viscosity influence is reinforced.

In Figs. 5 and 6 is presented the crankshaft torque variation with time. The oil viscosity augmentation also increases the crankshaft torque, i.e., the load necessary to be supplied by the electrical motor. But as we are simulating the system considering a very great difference in the evaporator and condenser pressures this influence is small in the present case, (c.f. Figs. 5 and 6). As can be seen in Fig. 6, the motor input voltage influences more the action of oil viscosity augmentation.

Conclusion. In the present paper is presented a simplified model to simulate the startup of hermetic refrigerating compressor. The results are physically coherent, meaning that the model is well implemented and that can be used to simulate this transient regime. The results show the oil viscosity influences over the electrical motor torque, the compressor load and crankshaft angular velocity with time considering two values of the motor input voltage. In the case of the lower motor input voltage equal to $97 \mathrm{~V}$ the compressor startup takes more than one second for the higher viscosity value. This points to the necessity of a correct design of the electric motor, the compressor mechanism and the use of the appropriate oil in the compressor operation range. More complete simulation are being carried out, considering the evaporator and condenser pressure variations, as well as the simulation of the main compression chamber in more details.

Disclosure. The authors report no conflicts of interest in this work. 


\section{References}

(1) Skovrup, M. WinDali - an open-structured component modeling and simulation program based on standard programming languages. Proceedings of SIMS Conference; 157-172, 2000.

(2) Link, R., Deschamps, C.J., Numerical modeling of startup and shutdown transients in reciprocating compressors, International Journal of refrigeration, 34, 1398-1414, 2011.

(3) Dutra, T., Deschamps, C.J., A simulation approach for hermetic reciprocating compressors including electrical motor modeling, International Journal of refrigeration, 59, 168-181, 2015.

(4) Gardenghi, A.R., Lacerda, J.F., Tibiriça, C.B., Cabezas-Gómez, L., Numerical and experimental study of the transient behavior of a domestic vapor compression refrigeration system - Influence of refrigerant charge and ambient temperature, Applied Thermal Engineering, 190, 116728, 2021.

(5) Uicker, J J, Pennock, GR, Shigley, JE. Theory of Machines and Mechanisms. 3rd Ed., Oxford University Press, USA, 2003.

(6) Rasmussen, BD. Variable speed hermetic reciprocating compressors for domestic refrigerators. Energy analysis and optimization. PhD Thesis, Department of Energy Engineering Energy Systems, Technical University of Denmark, ET-Ph.D 97-03, Denmark, 1997.

(7) Bukac, H. Modeling Compressor Start Up, Proceedings of International Compressor Technology Conference, Purdue University, 2002, C12-6. 